\title{
Mortality Facts in Internal Medicine Wards: A Descriptive Study from a University Hospital
}

\author{
Nursel Çalık Başaran*, [MD] \\ Burak Yasin Aktaş², [MD] \\ Yusuf Ziya Şener ${ }^{3}$, [MD] \\ Serdar Ceylan ${ }^{4}$, [MD] \\ Emre Yekedüz ${ }^{4}$, [MD] \\ Batuhan Başpınar ${ }^{4}$, [MD] \\ Cem Şimşek ${ }^{4}$, [MD] \\ Lale Özışık ${ }^{1}$, [MD] \\ Gülay Sain Güven ${ }^{1}$, [MD] \\ Şerife Gül Öz $z^{1}$, [MD] \\ Mine Durusu Tanrı̈ver ${ }^{1}$, [MD] \\ 1, Hacettepe University, Medical Faculty, Department of Internal \\ Medicine, Division of General Internal medicine \\ 2, Hacettepe University, Medical Faculty, Department of Internal \\ Medicine, Division of Oncology. \\ 3, Hacettepe University, Medical Faculty, Department of Cardiology \\ 4,Hacettepe University, Medical Faculty, Department of \\ Internal Medicine. \\ *Corresponding Author: Nursel Çalık Başaran, MD \\ Hacettepe University Medical Faculty, Department of \\ Internal Medicine, Division of General Internal medicine \\ Sıhhiye, 06100, Altındağ Ankara \\ e-mail:dr_nurselcalik@yahoo.com \\ phone: +903123053029 \\ DOI: https://doi.org/10.32552/2018.ActaMedica.332
}

\section{rep ABSTRACT Clew}

Objective: We aimed to determine the mortality rates and the causes of death in hospitalized patients in Internal Medicine Wards in a University Hospital.

Material and Methods: Medical records of patients who were hospitalized between 01 June 2014 and 31 May 2015 in Internal Medicine Wards of a University Hospital were reviewed and patients who died were examined retrospectively. Patient characteristics and causes of death were sorted out.

Results: In the defined time frame, 5314 hospitalization episodes of 4500 patients were recorded and $416(9.2 \%)$ patients died during hospital stay. The mean age of the patients who died was 62 (19-95) years and 54\% of them were male. The median duration of hospitalization was $16(0-142)$ days. The mean Charlson score was $6.3 \pm 2.7$. The rates of hospitalization and death did not differ between seasons. Malignancy was present in $71 \%$ of the cases and, $46 \%$ had metastatic solid cancer. The most common accompanying diseases were diabetes mellitus (25.7\%), hypertension (35\%) and congestive heart failure (18.8\%). The most common reasons of admission were respiratory distress (23.8\%), pneumonia (11.1\%), and general deterioration (10.6\%) among the patients who died. Sepsis $(69 \%)$ and respiratory failure $(15.9 \%)$ were the leading causes of deaths.

Conclusion: Patients who died in internal medicine wards have high chronic illness burden. Sepsis was the most common cause of death.

Keywords: Internal medicine, mortality, sepsis.

\section{INTRODUCTION}

"The internist" is basically described as "the doctor of adults [1]. The diagnosis, treatment, and follow-up of acute, chronic, single or multiple diseases as well as prevention of diseases in adults are within the scope of the practice of an internist. In recent years, leading institutions of internal medicine specialists such as the American College of Physicians and the European Federation of Internal Medicine put forward policy papers supporting an integrated approach [2]. Indeed, we are carrying out an integrated approach in patient management in our University Hospital, Department of Internal Medicine.

The prolongation of the expected life span, along with the progress in the diagnostic and therapeutic methods, are leading to more complicated patients with chronic diseases, along with frequent and long hospital admissions. According to US data, an increase of $11 \%$ was seen in hospital admissions between 2000-2010 [3]. According to the Turkish 
Ministry of Health data, in 2016 the number of total inpatients was closer to 13.5 million which was 5.5 million in 2000 [4]. The crude mortality rate was 23.9 per thousand in Turkish University Hospitals, and 19.4 per thousand in Turkey whereas hospital crude mortality rates for adult inpatients were $18.0 \%$ in $2009,24.0 \%$ in 2010 and $16.7 \%$ o in 2011 in our University Hospital [5].

In this study, we aimed to document the mortality rates of patients hospitalized in the Internal Medicine wards of a University Hospital and the most common diagnoses that are deemed to be responsible for the death.

\section{MATERIALS and METHODS}

The Internal Medicine wards of our University Hospital have 214 bed-capacity including intensive care units (ICU) and oncology wards. Medical records of patients who were hospitalized for at least 24 hours or overnight and who died between 01 June 2014 and 31 May 2015 in Internal Medicine wards were examined retrospectively. Patient characteristics and causes of death were sorted out. Data were obtained from medical records to gather demographic information, admission complaints, first admission place, primary hospitalization ward, accompanying diseases, ICU admission, need for mechanical ventilation, admission type (emergency / elective), immunosuppressive drugs (including steroids), acute phase reactants, complete blood count and blood chemistry results. The Charlson comorbidity score was calculated to standardize the disease burden of patients. The Charlson comorbidity score was first used in 1987 and is a scoring scale ranging from 0 to 33 points, predicting 10-year mortality as well as in-hospital mortality and updated and validated in $2011[6,7]$.

The reason for death was sorted out through a detailed review of all the records by the investigator team. Diagnosis of sepsis, severe sepsis, and septic shock were made according to consensus definitions that were in place during the time frame of the study. We used SIRS criteria to define inflammatory response and presence of infection was decided retrospectively by the two investigator based on clinical judgement in medical records [8]. We defined respiratory failure for both acute hypoxic and hypercapnic respiratory failure. Hypoxic respiratory failure was defined as a $\mathrm{PaO} 2 / \mathrm{FIO} 2$ ratio $\leq 300$ while receiving at least $40 \% \mathrm{FIO} 2$. In addition, patient had to receive non-invasive or invasive support for $>12$ hours for respiratory failure. $\mathrm{PaO} 2$ and $\mathrm{FIO} 2$ were extracted from respiratory flowsheet data including time-stamped recordings of supplemental oxygen and supportive modality [9]. Hypercapnic respiratory failure was defined as acute rise of $\mathrm{CO} 2$ levels in arterial blood samples $(>45 \mathrm{mmHg})$ that resulted in respiratory acidosis $(\mathrm{pH}<7.35)$ [10]. Patients who had acute coronary syndrome, malignant arrhythmia or congestive heart failure and systemic hypotension and hypoperfusion secondary to insufficient cardiac output were considered cardiogenic shock after other causes for hypotension were excluded[11].

\section{Statistical Analysis}

Data were analyzed in SPSS 21.0 (SPSS INC., Chicago, IL, USA) statistical program and descriptive statistics were used. Normally distributed numerical values were given as mean \pm standard deviation (SD), non-normally distributed numerical data were given as median (minimum-maximum), and non-parametric data as percentage (\%). The Chi-square or Fisher's exact test was used, where suitable, to compare categorical variables. Normally distributed numerical variables, hemoglobin and albumin, were compared with student t- test, and non-normally distributed numerical data were compared with Wilcoxon test. $95 \%$ confidence interval and $p$ value $\leq 0.05$ were considered significant.

day of each month, assistant doctors who examine patients throughout a month change and take theoretical training on practice of clinic. The training including the importance and methods of taking occupational history, and the relation between occupation and diseases is given to the new assistant doctor group as an extra 10 minutes' education session. In addition, they were informed for the observation of the occupational history ratios after this training. The difference of taking occupational history of hypertensive patients searched between two, trained and non-trained, physician groups. At the end of May, researchers screened electronic medical files of patients who diagnosed with hypertension (ICD10 code I10) of outpatients in General Internal Medicine Division in April and May 2018. Sociodemographic data, diagnosis time of hypertension, treatment status, accompanying chronic diseases, occupational history, exposures in workplace were collected from these medical files. Local ethical committee approved this trial.

\section{RESULTS}

A total of 5314 admissions that belong to 4500 patients were recorded in Internal Medicine 
Department wards, between 01 June 2014 and 31 May 2015. Of these, 416 patients (9.2\%) died during the hospital stay. The mean age of the patients who died was 62 (19-95) years and 188 (45\%) of them were 65 years-old or older (Table 1). The mean Charlson score was $6.3 \pm 2.7$ among the deceased patients. There was no statistical difference in duration of stay with regards to male gender or $\geq 65$ years of age or having cancer. Hospitalization and death rates did not show seasonal difference (Table 1). Median length of stay was 16 (0-142) days overall.

Table 1. Baseline characteristics of deceased patients $(n=416)$

\begin{tabular}{|c|c|}
\hline Characteristics of deceased patients & Value \\
\hline Age, median (min-max) year & $62(19-95)$ \\
\hline Male, n (\%) & $225(54)$ \\
\hline Charlson score, mean \pm SD & $6.3 \pm 2.7$ \\
\hline Body mass index, median (min-max) kg/m² & $26 \mathrm{~kg} / \mathrm{m}^{2}(16.4-50.4)$ \\
\hline $\begin{array}{l}\text { Seasonal distribution, } \mathrm{n}(\%)^{*} \\
\text { Spring } \\
\text { Summer } \\
\text { Fall } \\
\text { Winter }\end{array}$ & $\begin{array}{c}105(25.2) \\
112(26.9) \\
116(27.9) \\
83(20)\end{array}$ \\
\hline $\begin{array}{l}\text { Reason for hospitalization, } \mathrm{n}(\%) \\
\text { Medical treatment } \\
\text { Chemotherapy } \\
\text { Etiology research } \\
\text { Invasive procedure }\end{array}$ & $\begin{array}{l}375(90.1) \\
19(4.6) \\
13(3.1) \\
9(2.2)\end{array}$ \\
\hline Emergent hospitalization & $329(79.1)$ \\
\hline $\begin{array}{l}\text { Comorbid illness } \mathrm{n}(\%) \\
\text { Malignancy, total } \\
\text { Hematological } \\
\text { Solid organ, non-metastatic } \\
\text { Solid organ, metastatic }\end{array}$ & $\begin{array}{c}295(70.9) \\
77(18.4) \\
26(6.3) \\
192(46.2)\end{array}$ \\
\hline Hypertension & $149(35.8)$ \\
\hline Diabetes mellitus & $107(25.7)$ \\
\hline Coronary artery disease & $78(18.8)$ \\
\hline Congestive heart failure & $56(13.5)$ \\
\hline Chronic obstructive lung disease & $52(12.5)$ \\
\hline Chronic renal failure & $46(11.1)$ \\
\hline Cerebrovascular disease & 19(4.6) \\
\hline Rheumatoid arthritis & $11(2.6)$ \\
\hline Chronic liver diseases & $23(5.5)$ \\
\hline Chronic viral hepatitis & $12(2.9)$ \\
\hline Dementia/Alzheimer disease & $10(2.4)$ \\
\hline
\end{tabular}

There was no seasonal difference, $p=0.1$ 
The most common reasons of admission were respiratory distress (23.8\%), pneumonia (11.1\%), and general deterioration (10.6\%) among the patients who died (Table 2). "Other" reasons for hospitalization were very variable and constituted $32.6 \%$ of the total.

Table 2. Distribution of the admission diagnoses of the deceased patients, the treatments received during hospital stay and causes of death

\begin{tabular}{|c|c|}
\hline Admission diagnosis & Number (\%) \\
\hline Dyspnea & $99(23.8)$ \\
\hline Pneumoniae & $46(11.1)$ \\
\hline General deterioration & $44(10.6)$ \\
\hline Sepsis & $36(8.7)$ \\
\hline Chemotherapy & $25(6)$ \\
\hline Febrile neutropenia & $16(3.8)$ \\
\hline Gastrointestinal hemorrhage & $14(3.4)$ \\
\hline Others & $136(32.6)$ \\
\hline \multicolumn{2}{|l|}{ Treatment modalities during follow-up } \\
\hline Admission to the intensive care unit & $211(50.7)$ \\
\hline Antibiotic utilization & $392(94.2)$ \\
\hline Anticoagulant/antiplatelet utilization & $256(61.5)$ \\
\hline Corticosteroid utilization & $281(67.5)$ \\
\hline Immunosuppresive treatment & $188(45.2)$ \\
\hline Transfusion & $318(76.4)$ \\
\hline Hemodialysis & $75(18)$ \\
\hline \multicolumn{2}{|c|}{ Presence of invasive procedure, at least one } \\
\hline \multicolumn{2}{|l|}{ Vascular invasive procedure } \\
\hline \multicolumn{2}{|l|}{ Non-vascular invasive procedure } \\
\hline Surgical procedure & $304(73.1)$ \\
\hline \multicolumn{2}{|l|}{$222(53.3)$} \\
\hline \multicolumn{2}{|l|}{$129(31)$} \\
\hline \multicolumn{2}{|l|}{$11(2.6)$} \\
\hline Non- invasive mechanical ventilation & $196(471)$ \\
\hline Invasive mechanical ventilation & $213(51.2)$ \\
\hline \multicolumn{2}{|l|}{ Cause of death } \\
\hline Sepsis & $287(69)$ \\
\hline Respiratory failure & $66(15.9)$ \\
\hline Cardiac reasons & $24(5.8)$ \\
\hline Gastrointestinal hemorrhage & $9(2.2)$ \\
\hline Metabolic acidosis & $9(2.2)$ \\
\hline
\end{tabular}




\begin{tabular}{|l|c|}
\hline Multiorgan failure & $7(1.7)$ \\
\hline Pulmonary thromboembolism & $5(1.2)$ \\
\hline Disseminated intravascular coagulation & $4(1)$ \\
\hline Hepatic insufficiency & $2(0.5)$ \\
\hline Aortic dissection & $1(0.2)$ \\
\hline Pancreatitis & $1(0.2)$ \\
\hline Subarachnoid hemorrhage & $1(0.2)$ \\
\hline
\end{tabular}

Of the deceased cases, 180 (43\%) were initially hospitalized in oncology wards and 140 (33.7\%) were admitted to either intensive care unit or acute care unit. There were 295 (70.9\%) patients with a diagnosis of malignancy, 192 (46.2\%) of them had metastatic solid cancer (Table 1). The most common comorbidities, besides cancer, were hypertension (35\%), diabetes mellitus (25.7\%), and congestive heart failure (18.8\%) (Table 1). According to hospitalization status, 329 (79.1\%) were emergently hospitalized and $238(57.2 \%)$ of these were initially admitted to the emergency department. A total of 211 (50.7) patients were enrolled in ICU during their hospitalization, while 118 patients (27.9) were initially admitted to ICU. Non-invasive mechanical ventilation was performed in $47 \%$ of the cases and $51 \%$ were followed up with invasive mechanical ventilation. Eighteen percent of the cases underwent hemodialysis. At least one interventional procedure was done in $73.1 \%$ of the cases. Invasive vascular procedures were performed in 222 (53.3\%) patients (Table 1).
Sepsis was the leading cause of mortality and affected 287 patients (69\%), whereas, respiratory failure was the second cause of mortality and affected 66 patients (15.9\%) (Table 3). Median duration of ICU stay was 6 (0-133) days. The clinical characteristics of patients with regards to ICU admission are summarized in Table 3. Patients admitted to the ICU had significantly less frequency of malignant disease, than those not admitted to the ICU $(55.5 \%$ and $86.8 \%$, respectively) ( $p<0.001)$. Deceased patients who were admitted to ICU were more commonly transferred from the emergency room (Table 3 ). The mean Charlson score of the patients who were followed up in ICU was statistically significantly lower $(5.7 \pm 2.8$ vs $7.0 \pm 2.4$, respectively, $p<0.001)$ than those not followed in the ICU. There was no statistically significant difference in terms of length of hospital stay between the patients who were followed in the ICU and those who were not [median 17 (0132 days) vs. 15 ( $0-142$ days), $p=0.135$ ].

Table 3. Clinical features of deceased patients according to intensive care unit admission

\begin{tabular}{|c|c|c|c|}
\hline & $\begin{array}{l}\text { Cared in the intensive care } \\
\text { unit, } n=211\end{array}$ & $\begin{array}{l}\text { Cared out of intensive care } \\
\text { unit, } \\
n=205\end{array}$ & P value \\
\hline Age $\geq 65, n(\%)$ & 90 (47.9) & 98 (52.1) & 0.291 \\
\hline $\begin{array}{l}\text { Cause of death, n (\%) } \\
\text { Sepsis } \\
\text { Respiratory failure } \\
\text { Cardiac events } \\
\text { Other causes }\end{array}$ & $\begin{array}{l}153(53.3) \\
34(51.5) \\
11(45.8) \\
13(33.3)\end{array}$ & $\begin{array}{l}134(46.7) \\
32(48.5) \\
13(54.2) \\
26(66.7)\end{array}$ & 0.125 \\
\hline $\begin{array}{l}\text { Hospitalization status, n (\%) } \\
\text { Emergent } \\
\text { Elective }\end{array}$ & $\begin{array}{l}183(86.7) \\
28(13.3)\end{array}$ & $\begin{array}{l}146(71.2) \\
59(28.8)\end{array}$ & 0.125 \\
\hline $\begin{array}{l}\text { Admitted to emergency de- } \\
\text { partment, } n(\%)\end{array}$ & 138 (65.4) & $100(48.8)$ & $<0.001$ \\
\hline
\end{tabular}




\begin{tabular}{|c|c|c|c|}
\hline $\begin{array}{l}\text { Malignant diagnosis, n (\%) } \\
\text { No malignancy } \\
\text { Malignancy } \\
\text { Hematological } \\
\text { Solid, non-metastatic } \\
\text { Solid, metastatic }\end{array}$ & $\begin{array}{l}94(44.5) \\
117(55.5) \\
43(20.4) \\
12(5.7) \\
62(29.4)\end{array}$ & $\begin{array}{l}27(13.2) \\
178(86.8) \\
34(16.6) \\
14(6.8) \\
130(63.4)\end{array}$ & $<0.001$ \\
\hline Charlson score, mean \pm SD & $5.7 \pm 2.8$ & $7 \pm 2.4$ & $<0.001$ \\
\hline $\begin{array}{l}\text { Duration of stay, median } \\
\text { (min-max) }\end{array}$ & $17(0-132$ & $15(0-142$ & 0.135 \\
\hline
\end{tabular}

SD, standard deviation

\section{DISCUSSION}

Retrospective evaluation of a one-year data of a tertiary care university hospital demonstrated that $9.2 \%$ of the patients who were admitted to the internal medicine wards were deceased in the hospital. The deceased patients had a high baseline chronic disease burden, high prevalence of malignancy and long length of hospital stay. Respiratory symptoms and conditions were the main diagnoses at admission and most of the deceased patients were emergently hospitalized and half of them were admitted to the ICU at one point during their in-patient stay. Sepsis was the leading cause of death. Patients who were admitted to the ICU mostly entered the hospital from the emergency room, had lower prevalence of malignancy and lower burden of chronic diseases.

According to Turkish Health Ministry, the crude mortality rate in Turkey was 19.4 per thousand and to the NHCS data in the US $2 \%$ of the hospitalized patients died in 2010 [3]. The rather high in-patient mortality rate revealed in this study can be explained by the high disease burden of the hospitalized patients and the high frequency of malignant and probably end-stage patients. Hacettepe Adult Hospital crude mortality rate was reported to be between $16.7 \%$ and $24 \%$ in the years 2009 and 2011 [5]. The median length of hospital stay was also quite high, 16 days, when compared to the average length of hospital stay in Turkey which was reported as 5.7 days according to 2016 Health Ministry Data [4]. This number is 8.2 days in OECD countries, 6.1 days in the US and 7 days in England [4]. In the study conducted by Hall et al., the mean hospital stay of patients who were deceased in the hospital was 7.9 days, and it was significantly longer than patients who survived [3]. These data also reflect the complicated nature of the internal medicine patients assessed in this study. In our cohort of deceased patients, $96 \%$ of the patients had a Charlson score of
2 and above, suggesting that very complicated and severely ill patients were hospitalized. Actually, this fact is not peculiar to our hospital or country, but rather a reality of patients cared by internists as implicated by Bai and friends. Nearly half of the patients in the internal medicine services were found to have a Charlson score of 2 and above [12]. The world population is getting older as the average life expectancy was 72 years-of a-age in 2016 with high chronic diseases burden [13]. Non communicable diseases as heart diseases, stroke, chronic respiratory diseases, diabetes and cancer are increasingly high and responsible for $71 \%$ of global deaths. Beside leading causes of deaths, the chronic diseases bring the high usage of health services, insurance systems and high financial burden.

Sepsis was the cause of mortality in more than twothirds of the patients in the internal medicine wards in this study. The increasing elderly population, patients with multiple chronic medical diseases and frequent health care system admissions, prolonged life due to advances treatment in cancer patients are the predisposing factors for infections and increases the prevalence of sepsis. Increased frequency of sepsis, as well as increased infections due to resistant microorganisms make treatment more difficult in sepsis and increase mortality. Hall et al reported that $6.3 \%$ of deaths was due to septicemia, $16.5 \%$ due to respiratory failure, and highlighted an increase in deaths due to sepsis from year 2000 to 2010 [3]. In a study conducted by examining the diagnostic codes of death certificates in the UK population between 2001 and 2010, it was reported that $6.9 \%$ of all deaths were due to sepsis [14]. One-third to one-half of deaths were associated with sepsis in two separate cohorts of in-hospital deaths reported by Liu et al., and most of these patients were septic at the time of admission[15]. In a retrospective study of in-hospital mortality conducted in 2014 by 
Rhee et al., it was reported that $6 \%$ of total hospitalized patients and $35 \%$ of all deaths were due to sepsis and the sepsis rates remained constant over the years [16]. Since these rates represents different hospitals and population, they cannot be directly compared with our numbers. However, it is clear that overall, sepsis is an important and increasing cause of hospitalization and in-hospital deaths over the years though increased awareness and early treatment reduced the mortality from sepsis.

It's always a question mark in terms of patient safety and healthcare quality, do holidays and decreased staff numbers have adverse consequences on patient care? We could not observe any difference in distribution of admissions and deaths with regards to the seasons, suggesting that the variations in staff numbers and working hours had no adverse effects on hospital mortality during holiday seasons.

Respiratory symptoms and conditions are a major category of diagnoses in internal medicine admissions. In a study which reviewed the hospital admissions to the Internal Medicine services throughout Europe in 2010, breathlessness (dyspnea), chest pain and abdominal pain were the leading symptoms of the patients [17]. The findings from this and such other studies are also important in terms of setting the targets for and shaping the training curriculum of internal medicine training.

A remarkable point in our study is that only half of the deceased patients were followed up in the ICU. According to the Charlson score, patients died out of the ICU are more severe than those died in the ICU. This situation can be interpreted as those patients who were not admitted ICU were having advanced malignancy or were terminal patients who needed palliative care. Likewise, only thirty percent of the patients with metastatic solid malignancy were followed up in the ICU. Moreover, nearly half of the patients with sepsis and respiratory failure could not be followed in the ICU. This emphasizes the importance of ICU bed requirements and the rational use of ICU beds for patients. Effective endof-life care of terminal patients, either oncologic or non-oncologic diseases, are one of the areas that should be developed for the rational use of health resources.

The limitation of our study is the retrospective design. The causes of death were decided by reviewing the electronical records and the vital signs of the patients were not recorded. However, two researchers' reviewed electronic records and discharge reports, determined the causes of death independently to reduce the errors that could occur in the study.

In conclusion, this study demonstrated that quite high numbers of patients admitted to the internal medicine wards were deceased in the hospital. The deceased patients had a high baseline chronic disease burden, high prevalence of malignancy and long length of hospital stay. Sepsis and respiratory failure were the leading causes of death, although half of the patients with these diagnoses could not be/were not admitted to the ICU. The findings from this study are helpful in shaping the training curricula of the internal medicine residents and in making decisions for allocation of healthcare resources in an aging population and a rapidly evolving era of health.

\section{ACKNOWLEDGEMENT}

There is no acknowledgement.

\section{CONFLICT Of INTEREST STATEMENT}

The authors declare they have no conflicts of interest

\section{re) REFERENCES Cem}

[1] Steven E, Weinberger MD, Anne G et al. Competency-Based Education and Training in Internal Medicine. Ann Intern Med 2010; 153: 751-56.

[2] Tanriover MD, Rigby S, van Hulsteijn LH et al. What is the role of general internists in the tertiary or academic setting? Eur J Intern Med 2015; 26(1): 9-11.

[3] Hall MJ, Levant S, DeFrances CJ. Trends in inpatient hospital deaths: National Hospital Discharge Survey, 2000-2010. NCHS Data Brief 2013; 118: 1-8.

[4] T.C. Sağlık Bakanlığı Sağlık İstatistikleri Yıllığı 2016. https:// dosyasb.saglik.gov.tr/Eklenti/13183,sy2016turkcepdf.pdf (accessed June 2018).

[5] Erbaydar NP, Çilingiroğlu N, Pişkin TM et al. Analysis of three-year death record of Hacettepe University Adult Hospital. Acta Medica 2013; 43: 8-15.

[6] Charlson ME, Pompei P, Ales KL et al. A new method of classifying prognostic comorbidity in longitudinal studies: development and validation. J Chronic Dis 1987; 40: 373-83.

[7] Quan H, Li B, Couris CM et al. Updating and validating the Charlson comorbidity index and score for risk adjustment in hospital discharge abstracts using data from 6 countries. Am J Epidemiol 2011; 173: 676-82.

[8] Levy MM, Fink MP, Marshall JC et al. 2001 SCCM/ESICM/ACCP/ ATS/SIS International Sepsis Definitions Conference. Crit Care Med 2003; 31: 1250-6.

[9] Bellani G, Laffey JG, Pham T et al. Epidemiology, Patterns 
of Care, and Mortality for Patients With Acute Respiratory Distress Syndrome in Intensive Care Units in 50 Countries. JAMA 2016; 315: 788-800.

[10] Davidson AC, Banham S, Elliott M et al. BTS/ICS guideline for the ventilatory management of acute hypercapnic respiratory failure in adults. Thorax 2016; 71(Suppl 2): ii1-35.

[11] Califf RM, Bengtson JR. Cardiogenic shock. N Engl J Med 1994; 330: 1724-30.

[12] Bai AD, Srivastava S, Tomlinson GA, et al. Mortality of hospitalised internal medicine patients bedspaced to non-internal medicine inpatient units: retrospective cohort study. BMJ Qual Saf 2018; 27: 11-20.

[13] World Health Organization, Global Health Observatory (GHO) Data. http://www.who.int/gho/mortality_burden_disease/ en/ (accessed June 2018).

[14] McPherson D, Griffiths C, Williams M, et al. Sepsis-associated mortality in England: an analysis of multiple cause of death data from 2001 to 2010. BMJ Open 2013; 3:e002586.

[15] Liu V, Escobar GJ, Greene JD, et al. Hospital deaths in patients with sepsis from 2 independent cohorts. JAMA 2014; 312: 90-2.

[16] Rhee C, Dantes R, Epstein L, et al. Incidence and Trends of Sepsis in US Hospitals Using Clinical vs Claims Data, 20092014. JAMA 2017; 318: 1241-49.

[17] Duckitt R, Palsson R, Bosanska L, et al. Common diagnoses in internal medicine in Europe 2009: a pan-European, multi-centre survey. Eur J Intern Med 2010; 21: 449-52. 